\title{
Assessment of scale effects in the experimental evaluation of the coefficient of friction of sliding isolators
}

Virginio Quaglini ${ }^{\mathrm{a} *}$, Paolo Dubini ${ }^{\mathrm{a}}$, Marco Furinghetti ${ }^{\mathrm{b}, \mathrm{c}}$ and Alberto Pavese ${ }^{\mathrm{c}}$

${ }^{a}$ Department of Architecture, Built Environment and Construction Engineering. Politecnico di Milano, Piazza Leonardo da Vinci 32, 20133 Milano, Italy;

${ }^{b}$ EUCENTRE, European Centre for Training and Research in Earthquake Engineering, Via A. Ferrata 1, 27100 Pavia, Italy;

${ }^{c}$ Department of Civil Engineering and Architecture, University of Pavia, Via A. Ferrata 3, 27100 Pavia, Italy.

${ }^{(*)}$ corresponding author

Email: virginio.quaglini@polimi.it

Phone: +39 02.2399.4248 


\section{ABSTRACT}

Sliding bearings have been extensively used to implement base isolation design in civil engineering works. Testing of isolators is conducted for characterizing the design properties to be used in structural analysis, as well as for verifying the performance of the devices before their application. The quantification of the effects of scaling specimens and testing on the observed coefficient of friction is an issue, due to the nonlinear dependence of the latter on several factors like load, velocity and temperature. An effort to quantify such effects is pursued in the study. The coefficient of friction is parameterized as a function of few dimensionless quantities related to heating of the sliding surfaces, and similarity conditions are assessed under which the influence of scaling is below normal production variability.

\section{Keywords}

Coefficient of friction; sliding isolation system; test scaling; frictional heating; dimensionless number. 


\section{Conflict of Interests}

The authors declare that there is no conflict of interests regarding the publication of this paper.

\section{Acknowledgements}

Part of the current work has been carried out under the financial support of the Italian Civil Protection, in the frame of the national Research Project DPC - ReLUIS (National Network of Laboratories of Seismic Engineering) 2014-2018, Line 6 - Isolation and Dissipation 


\section{INTRODUCTION}

Sliding bearings have been extensively used as part of seismic isolation systems for buildings, bridges and critical infrastructures, to support the weight of the structure and permit horizontal movements with minimal resistance [Buckle and Mayers; 1990, Dolce et al., 2005; Calvi and Calvi, 2018. The simplest sliding isolation device is the Pure Friction (P-F) system [Westermo and Udwadia, 1983; Mostaghel and Tanbakuchi, 1983; Younis and Tadjbakhsh, 1984; Jangid, 1996], consisting of a flat PTFE slider and a mating steel plate that separate the superstructure from the substructure. However, this system has no any re-centering capacity, and it can suffer from large residual displacements after strong earthquakes, which make it unsuitable for important structures. Sliding systems with restoring force have been proposed such as the Resilient-Friction Base Isolation System [Mostaghel, 1984], where rubber elements are used to produce a re-centering effect, the Shape Memory Alloy (SMA) Isolation System [Dolce et al., 2000], and the Curved Surface Slider (CSS), or Friction Pendulum System ${ }^{\circledR}$ [Zayas et al., 1987; Zayas et al., 1990; Mokha et al., 1996], which provides a restoring effect by an articulated slider that moves on a concave surface. In the last decade sliding bearings with curved surfaces have increasingly gained the favour of structural engineers, and today they are one of the most popular isolation systems in many countries worldwide [Martelli et al., 2014].

In its simplest version, the CSS consists of two concave steel plates and an intermediate convex slider. A sliding surface is formed between the slider and either concave plate: the primary surface accommodates the horizontal displacement of the superstructure, whereas the secondary surface accommodates the rotation. At each sliding surface, the slider is lined with a pad of thermoplastic material, like e.g. Polytetrafluoroethylene (PTFE) or Ultra High Molecular Weight PolyEthylene (UHMWPE), and the mating surface is made of a corrosion-resistant metal, like stainless steel or chromium plated carbon steel. Though improved versions of the CSS have been proposed in the last decade, e.g. the Double Concave Surface Slider [Fenz and Constantinou, 2006] and the Triple Friction Pendulum [Fenz and Constantinou, 2008; Morgan and Mahin, 2010], their mechanical behaviour 
follows the same principle. The horizontal force of CSS accounts for two contributions, namely the elastic force $F_{1}$, i.e. the product of the restoring stiffness $k=N / R$ times the horizontal displacement $d$, where $N$ is the vertical load acting on the bearing and $R$ is the effective radius of curvature [AlHussaini, 2004], and the friction force $F_{2}$ given by $\mu$ times $N$, where $\mu$ is the coefficient of friction of the sliding material:

$$
F=F_{1}+F_{2}=\left(\frac{N}{R} \cdot d+\mu \cdot N\right)
$$

In a Pure-Friction, or flat sliding isolator the restoring stiffness is zero and the reaction force coincides with $F_{2}$.

The coefficient of friction is a fundamental property for the performance of sliding isolation systems. Friction is the mechanism by which the seismic energy is dissipated, and high friction is beneficial for increasing the damping and limiting the displacement during an earthquake, but it also enlarges the horizontal reaction force of the isolation system, and reduces its re-centring capability [Quaglini et al., 2017a; Quaglini et al., 2017b].

Experimental studies [Zayas et al., 1989; Al-Hussaini, 2004; Constantinou et al., 2007; Mokha et al., 1998; Mokha et al., 1990; Mokha et al., 1991; Mokha et al., 1993; Dolce et al., 2005; Lomiento et al., 2013; Pavese et al., 2019; Furinghetti et al., 2019] demonstrated that the coefficient of friction of sliding isolators is affected from a number of factors, among which the normal load acting on the sliding surface, the velocity of sliding, and the surface temperature of are the most important. Another issue affecting the performance of sliding isolators subjected to fast movements is the decrease of the friction coefficient with the travelled distance, also named as cyclic effect [Mokha et al., 1991; Chang et al., 1990; Mosqueda et al., 2004a], which results from the heating of the sliding surface caused by energy dissipation [Mosqueda et al., 2004a; Quaglini et al., 2014]. Validated models that describe the variation of the coefficient of friction with normal load and velocity have been coded in software programs for structural analysis, like e.g. SAP 2000 and OpenSees [Tsai, 1997; SAP2000, 2013; Mosqueda et al., 2004b; McKenna et al., 2000], but few mathematical formulations have been 
developed to date to incorporate the cyclic effect [Lomiento et al., 2013; Kumar et al., 2015; Gandelli et al., 2018]. Though large testing programs were completed in the last two decades on sliding isolators in several laboratories around the world, the test protocols were often "project specific" and their results proved to be of difficult correlation for the definition of a performance model [Lomiento et al., 2013]. The influence of the overall dimensions of the bearing and of the trajectory of the slider on the release of heat is still an uncovered topic [Furinghetti et al., 2019; Quaglini et al., 2019], and this has prevented the formulation of general models valid for different scaling and loading situations.

Testing of isolators is prescribed from the standards for characterizing the properties of the isolation system for use in structural analysis and design, and for verifying, in qualification and quality control testing the actual properties of production devices before using in applications. For flat and curved surface sliders, current standards [CEN EN 15129, 2009; AASHTO, 2014; ASCE/SEI 7, 2017] recommend to test full scale prototypes; testing of scaled specimens is not allowed, and extrapolating the properties assessed on a prototype to devices with different size is permitted only for small dimensional changes between the reference and the new device, i.e. maximum $\pm 20 \%$ difference in design vertical load and/or displacement capacity [CEN EN 15129]. Unidirectional protocols are usually specified because easy to implement, though their reliability has been questioned, because during real earthquakes the motion is multi-directional, and heating of the surfaces is expected to be affected by the actual trajectory of the slider. However, in case of large isolators it can be not feasible to conduct tests at full scale, due to the little number of facilities worldwide with enough capacity; in addition, very large bearings cannot be tested in any facility (to the knowledge of the Authors the maximum load bearing capacity today available is $70000 \mathrm{kN}$ at Caltrans Seismic Response Modification Device (SRMD) Test Facility [Benzoni and Seible, 1998]). Scaled specimens of isolators are frequently tested for research, in order to reduce the experimental cost or to match the capacity of the equipment, like e.g. in shake table tests on base-isolated structural mock-ups [Becker and Mahin, 2011; Ponzo et al., 2017; Quaglini et al., 2017a; Wen et al., 2019]. However, while conditions for 
similarity between small and large scale structural models are well known and easy to implement [Harris and Sabnis, 1999], equivalent conditions for friction-based sliding systems are not defined and left to the Structural Designer to establish. Though the quantification of scale effects on the assessment of the coefficient of friction is of concern for both researchers and manufacturers, this issue is at the moment poorly investigated. Constantinou and co-workers developed a scaling methodology based on calculating the temperature history at the sliding surface of the production isolator subjected to bidirectional motion and replicating it at the sliding surface of the scaled isolator under an equivalent unidirectional protocol [Constantinou et al., 2007]. Another example for designing qualification testing of a large isolator used in offshore structures carrying load of about 10000 tons was presented by Fenz [Fenz et al., 2011]. However, in both cases, the influence of temperature on friction was unknown, and the coefficient of friction was assumed as temperature-independent, which is not realistic. An experimental procedure for assessing the coefficient of friction of sliding materials using a scaled model of flat slider was presented by Quaglini [Quaglini et al., 2009, Quaglini et al., 2012a] and validated in a particular application [Quaglini, 2012b], but general conditions for extrapolating the properties from small size models to the application were not investigated.

An effort to quantify the scale effects on the assessment of the coefficient of friction of sliding isolators is made in the present research. Tests at different scales, and including both production prototypes of sliding bearings and small size models, are performed. By expressing the coefficient of friction as a function of dimensionless parameters, the influence of scale factors is analysed and similarity conditions between models and prototypes is explored. 


\section{THEORETICAL BACKGROUND}

\section{Physical model of the sliding system}

Mechanical work must be supplied to sliding bearings to overcome the friction force and maintain the motion, and the most of this work is dissipated by friction at the contact area between the slider and the mating plate. By assuming that all the dissipated energy is converted into heat, the instantaneous heat flux $q(t)$ per unit area is given by

$$
q(t)=\mu(t) \cdot p(t) \cdot|v(t)|
$$

where $\mu$ is the kinetic coefficient of friction, $p$ is the pressure at the contact area and $v$ is the velocity [Quaglini et al., 2014]. The situation of a sliding isolator undergoing unidirectional motion, as in the qualification and quality control tests prescribed by the standards, is now considered. The contact problem can be reduced to the problem of a stationary body 1 (the sliding plate) in contact with a sliding body 2 (the slider) moving at relative velocity $v$. Heat is introduced into the system from a source moving with body 2 , having the shape of the contact surface of the slider. The intensity of the source is given by Eq. (2); a portion, $q_{1}$, of the heat flux enters body 1, and the remaining flux, $q_{2}=(1-p) q$, enters body 2 , where $p=q_{1} / q$ is the heat partition factor. Assumptions are now introduced to simplify the reference problem:

(a) the heat source acts over a small part of the stationary body 1 , so that the body 1 can be treated as a semi-infinite solid. Though the real problem is for a body of finite dimensions, when the interest is for the temperature generated over a small area of a large surface the assumption of semi-infinite solid should be anyhow valid [Carslaw and Jaeger, 1959];

(b) the surface of the stationary body 1 crossed by the heat source moving with body 2 is flat; in case of CSS the assumption is valid when the radius of curvature of the sliding surface is sufficiently large with respect to the amplitude of motion that the effect of curvature can be considered negligible; 
(c) all the heat generated by the source is supplied to body 1 , i.e. the heat partition factor $p=1$. This assumption is justified from the large thermal conductivity and thermal diffusivity of steel by comparison to those of the thermoplastic material lining the slider, and was confirmed by numerical analyses [Quaglini et al., 2014], where partition factors as large as $p=0.99$ were observed;

(d) the heat flux is not, in general, constant over the slider surface, due to dependencies of the friction force (per unit area) on velocity and on pressure distribution; an average value of the heat flux is instead considered where in Eq. (2) $p(t)$ is the average pressure on the contact area and $v(t)$ the average velocity at time $t$ so that the analysis for the temperature rise will be on an average value;

(e) the heat flux occurs only perpendicularly to the contact area between bodies 1 and 2, and adiabatic boundary conditions apply outside the contact region. This assumption is realistic when short time intervals are considered.

To replicate the unidirectional motion of the slider, the body 2 is considered to move with displacement $d(t)=A \sin (\omega t)$ and velocity $v(t)=A \omega \cos (\omega t)$, where $A$ is the oscillation amplitude and $\omega$ the circular frequency; the peak velocity is $v_{\mathrm{o}}=A \omega$.

\section{Dimensional analysis}

Upon some realistic assumptions, the temperature rise at the contact area between the slider and the mating surface in a sliding isolation system can be reduced to the simpler problem of the contact temperature between an oscillating heat source and a semi-infinite body. For such problem, at any time $t$ the temperature rise $T(x, y, z, t)$ at any point in the semi-infinite body 1 due to a quantity of heat supplied by the moving source is described by a basic set of parameters [Jaeger, 1942]: the dimension of the heat source $a$ (e.g. the radius in case of a circular source), the heat flux $q$, which depends on coefficient of friction $\mu$ and the average pressure $p$ over the contact area between the source and body 1 , the circular frequency $\omega$ and the amplitude $A$ of the motion, the thermal conductivity $k$ and the thermal 
diffusivity $\kappa=k /\left(\rho c_{p}\right)$ of the semi-infinite solid ( $\rho=$ mass density; $c_{p}=$ heat capacity). The contact temperature between body 1 and the heat source affects the coefficient of friction $\mu$, which is the variable of interest. Thereby attention is restricted hereinafter to the (average) temperature at the contact area between the moving heat source and the body 1, which will be denoted as $T$.

By invoking the Buckingham Pi theorem of dimensional analysis [Buckingham, 1914], the units can be rearranged and the system can be described with three dimensionless groups formed from the basic parameter set, namely the non-dimensional amplitude $\bar{A}$, the non-dimensional frequency $\bar{\omega}$ and the non-dimensional temperature $\bar{T}$

$$
\bar{A}=\frac{A}{a} \quad \bar{\omega}=\frac{a^{2} \cdot \omega}{4 \cdot \kappa} \quad \bar{T}=\frac{T \cdot k}{2 \cdot a \cdot q}
$$

These dimensionless numbers plus the independent variable $p$, which influences the coefficient of friction according to an independent mechanism, e.g. [Mokha et al., 1990], account for all the variables governing the problem, and the non-dimensional contact temperature can be parametrized as a function of the non-dimensional frequency and the non-dimensional amplitude of motion [Wen and Khonsari, 2007]. By requiring that the dimensionless parameters will stay constant for both the test conducted on a scaled specimen and for the application, they can be used to formulate scaling laws for the test.

A dimensionless parameter typically used to characterize moving heat source problems it the Péclet number, $P e$, that represents the ratio of the rate of heat advection by the flow (i.e the amount of heat introduced in the system by the moving source) to the rate of heat diffusion through the solid driven by an appropriate thermal gradient [Incoprera and De Witt, 2007]. The product of $\bar{A}$ and $\bar{\omega}$ can be interpreted as the Péclet number for the oscillation case, $P e=\frac{a \cdot A \omega}{4 \cdot \kappa}$. When the Péclet number is great, heat transport by advection is predominant; the heat will diffuse only a short distance into the solid in the time taken for the heat source to cross the heated zone, and the heat flux will then be approximately perpendicular to the heat source surface at all points; a large temperature gradient develops across the area of the heat source [Carslaw and Jaeger, 1959]. On the contrary, for small Pe numbers, heat 
diffusion through the solid is considered as the dominant transport mechanism, and the temperature distribution across the area of the heat source is expected to be smooth and almost uniform. In case of stationary heat source, $P e$ equals to zero. 


\section{MATERIALS AND METHODS}

\section{Prototype tests}

The tests were performed on the Flat Slider (FS) device sketched in Figure 1 [Furinghetti, 2015]. The device consists of a slider locked into a lower steel backing plate, and a flat sliding plate lined with a $2 \mathrm{~mm}$ thick stainless steel sheet, finished to $\mathrm{R}_{\mathrm{a}}=0.2 \mu \mathrm{m}$ roughness. A circular pad of a thermoplastic sliding material is housed for about half of its thickness into a recess machined in the slider. Two sliding materials were assessed in the experiments, namely PTFE filled with bronze and PTFE filled with solid lubricant; hereinafter the materials will be designed as MAT_A and MAT_B in order to avoid reference to commercial products. The choice of the FS device was motivated by the need to reduce the experimental costs, since the same backing plate could accommodate sliding pads of different diameter by simply changing the slider; nonetheless, the results are deemed to be applicable to the CSS as well, as it will be discussed later. In the study, pads of 160, 260 and $400 \mathrm{~mm}$ were assessed. 


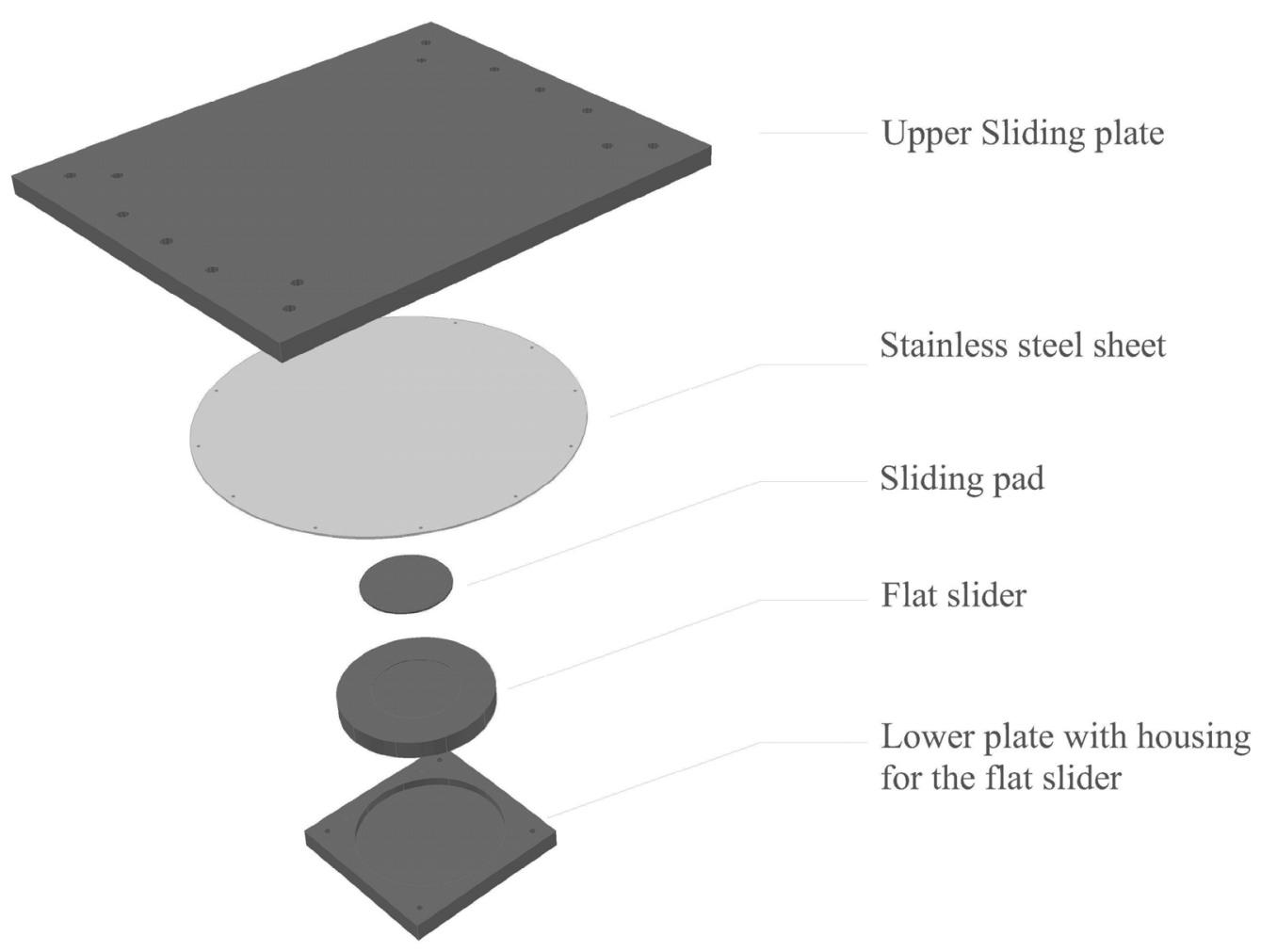

Figure 1. Sketch of the Flat Slider (FS) device [Furinghetti, 2015]

The FS was tested at the Eucentre facility in Pavia, Italy, using the Bearing Tester System (BTS) [Calvi et al., 2005]. The test protocol is illustrated in Table 1. Experiments were performed at different levels of contact pressure and slide velocity; at each velocity, three cycles were performed in the horizontal direction according to a sine waveform $d(\mathrm{t})=A \sin (\omega t)$, where $d$ is the displacement between the upper and the lower plates of the bearing, $A$ is the displacement amplitude and $\omega$ is the circular frequency, but at the lowest velocity $(0.6 \mathrm{~mm} / \mathrm{s})$ only a single cycle was performed at constant rate. However, at this speed the gap between the actual test velocity and the peak velocity $(0.94 \mathrm{~mm} / \mathrm{s})$ which would be developed in a harmonic test with average speed of $0.6 \mathrm{~mm} / \mathrm{s}$ is sufficiently little to be deemed as not relevant. 
Table 1. Test matrix for prototype tests.

\begin{tabular}{|c|c|c|c|c|}
\hline Test & $\begin{array}{c}\text { pad pressure } \\
P \\
(\mathrm{MPa}) \\
\end{array}$ & $\begin{array}{c}\text { amplitude } \\
A \\
(\mathrm{~mm}) \\
\end{array}$ & $\begin{array}{c}\text { peak velocity } \\
v_{\mathrm{o}} \\
(\mathrm{mm} / \mathrm{s}) \\
\end{array}$ & $\begin{array}{c}\text { cycles } \\
n \\
(\#) \\
\end{array}$ \\
\hline \multirow{6}{*}{ D1 } & \multirow{6}{*}{15} & \multirow{6}{*}{100} & 0.6 & 1 \\
\hline & & & 5 & 3 \\
\hline & & & 20 & 3 \\
\hline & & & 50 & 3 \\
\hline & & & 100 & 3 \\
\hline & & & 200 & 3 \\
\hline \multirow{6}{*}{ D2 } & \multirow{6}{*}{33} & \multirow{6}{*}{100} & 0.6 & 1 \\
\hline & & & 5 & 3 \\
\hline & & & 20 & 3 \\
\hline & & & 50 & 3 \\
\hline & & & 100 & 3 \\
\hline & & & 200 & 3 \\
\hline \multirow{6}{*}{ D3 } & \multirow{6}{*}{45} & \multirow{6}{*}{100} & 0.6 & 1 \\
\hline & & & 5 & 3 \\
\hline & & & 20 & 3 \\
\hline & & & 50 & 3 \\
\hline & & & 100 & 3 \\
\hline & & & 200 & 3 \\
\hline \multirow{3}{*}{ D4 } & \multirow{3}{*}{60} & \multirow{3}{*}{100} & 0.6 & 1 \\
\hline & & & 50 & 3 \\
\hline & & & 200 & 3 \\
\hline
\end{tabular}

The coefficient of friction $\mu$ was determined at each cycle in accordance to the formula [CEN EN 15129, 2009]:

$$
\mu=\frac{E D C}{4 \cdot A \cdot N}
$$

where $E D C$ is the Energy Dissipated per Cycle, i.e. the area of the force - displacement loop, $A$ has been already defined and $N$ is the vertical load acting on the bearing. 


\section{Small scale tests}

Tests were conducted according to the procedure presented in a previous work [Quaglini et al., 2009; Quaglini et al., 2012a] on a scaled model of flat bearing incorporating a specimen of either MAT_A or MAT_B. The specimen of sliding material consisted of a circular pad, $75 \mathrm{~mm}$ in diameter by $8 \mathrm{~mm}$ in thickness, recessed for $5 \mathrm{~mm}$ into a steel plate, in compliance with the provisions of the European standards for sliding bridge bearings and seismic isolators [CEN EN 1337-2, 2004; CEN EN 15129, 2009]. The mating surface was a mirror-finished stainless steel plate.

The testing protocol is illustrated in Table 2. At each pressure level, an unidirectional displacement history of the type $d(\mathrm{t})=A \sin (\omega t)$ was applied to the specimen. To fit the capacity of the testing machine, the displacement amplitude was set to $A=10 \mathrm{~mm}$, and the frequency was adjusted to produce a range of peak velocities $v_{\mathrm{o}}$ from $0.6 \mathrm{~mm} / \mathrm{s}$ to $200 \mathrm{~mm} / \mathrm{s}$. For each combination of pressure and frequency, 30 cycles of motion were performed, corresponding to an accumulated path of 1.2 meters, but at very low speed $(0.6 \mathrm{~mm} / \mathrm{s}) 10$ cycles only were performed. 
Table 2. Test matrix for small scale tests.

\begin{tabular}{|c|c|c|c|c|}
\hline Test & $\begin{array}{c}\text { pad pressure } \\
P \\
(\mathrm{MPa}) \\
\end{array}$ & $\begin{array}{c}\text { amplitude } \\
A \\
(\mathrm{~mm}) \\
\end{array}$ & $\begin{array}{c}\text { peak velocity } \\
v_{\mathrm{o}} \\
(\mathrm{mm} / \mathrm{s}) \\
\end{array}$ & $\begin{array}{c}\text { cycles } \\
n \\
(\#) \\
\end{array}$ \\
\hline \multirow{4}{*}{ M1 } & \multirow{4}{*}{15} & \multirow{4}{*}{10} & 0.6 & 10 \\
\hline & & & 50 & 30 \\
\hline & & & 100 & 30 \\
\hline & & & 200 & 30 \\
\hline \multirow{4}{*}{ M2 } & \multirow{4}{*}{33} & \multirow{4}{*}{10} & 0.6 & 10 \\
\hline & & & 50 & 30 \\
\hline & & & 100 & 30 \\
\hline & & & 200 & 30 \\
\hline \multirow{4}{*}{ M3 } & \multirow{4}{*}{45} & \multirow{4}{*}{10} & 0.6 & \multirow{4}{*}{$\begin{array}{c}10 \\
30 \\
3030\end{array}$} \\
\hline & & & 50 & \\
\hline & & & 100 & \\
\hline & & & 200 & \\
\hline \multirow{4}{*}{ M4 } & \multirow{4}{*}{60} & \multirow{4}{*}{10} & 0.6 & 10 \\
\hline & & & 50 & 60 \\
\hline & & & 100 & 60 \\
\hline & & & 200 & 60 \\
\hline
\end{tabular}




\section{RESULTS}

The tests performed on the prototypes and the scaled model of FS are analysed to appraise the effect of scale on the coefficient of friction. In order to compare the distances travelled in the tests performed at different scales, a non-dimensional distance is used hereinafter

$$
\bar{d}=\frac{S_{d}}{4 \cdot d_{b d}}
$$

where $S_{d}$ is the accumulated slide distance at a given time step, and $d_{b d}$ is the design displacement of the reference prototype. For the present analyses $d b d=100 \mathrm{~mm}$ is assumed.

\section{Effect of the amplitude}

Four values of the non-dimensional amplitude $\bar{A}$ defined by Eq. (3a) were examined in the tests, namely $\bar{A}=0.50, \bar{A}=0.77, \bar{A}=1.25$, and $\bar{A}=0.27$; the first three values correspond to FS prototypes with pad radius $a=200 \mathrm{~mm}, a=130 \mathrm{~mm}$, and $a=80 \mathrm{~mm}$ respectively, and the latter to the small scale specimen with $a=37.5 \mathrm{~mm}$.

Figures 2 and 3 illustrate the coefficient of friction at different pressure levels and sliding speeds observed after a non-dimensional distance $\bar{d}=3\left(\bar{d}=1\right.$ for $\left.v_{\mathrm{o}}=0.6 \mathrm{~mm} / \mathrm{s}\right)$, corresponding to an accumulated slide path $S_{d}=1200 \mathrm{~mm}\left(S_{d}=400 \mathrm{~mm}\right.$ for $\left.v_{\mathrm{o}}=0.6 \mathrm{~mm} / \mathrm{s}\right)$. If the tests performed at $p=$ $15 \mathrm{MPa}$ are ignored, the coefficient of friction appears to be substantially independent of the nondimensional amplitude. At high speeds $\left(v_{\mathrm{o}} \geq 50 \mathrm{~mm} / \mathrm{s}\right) \mu$ shows variations less than $-10 \%$ for $\bar{A}$ ranging between 0.27 and 1.25 , while at low speeds $\left(5 \leq v_{0} \leq 20 \mathrm{~mm} / \mathrm{s}\right)$ changes are less than $-12 \%$ for $0.50 \leq$ $\bar{A} \leq 1.25$. Only at $v_{\mathrm{o}}=0.6 \mathrm{~mm} / \mathrm{s}$ discrepancies in the friction coefficient of more than $20 \%$ are observed. At $p=15 \mathrm{MPa}$, unlike the general trend, the coefficient of friction increases with increasing of $\bar{A}$ whichever the velocity.

From a physical point, when the amplitude of motion is small in comparison to the radius of the pad, the situation approaches the one of a steady heat source, and the mating surface is subjected to an 
approximately constant heat flux. When the amplitude of motion is large in comparison to the radius of the pad (e.g. test with $\bar{A}=1.25$ ), the oscillating motion of the slider spreads the heat over a wider area of the mating surface, and the resulting intermittent heat flux is expected to induce a lower the temperature rise. However, at moderate and high pressures $(p \geq 15 \mathrm{MPa})$ and speeds the rate of heat introduced in the system by the moving source is much larger than the rate of heat diffusion through the steel plate, and an uniform temperature condition is achieved over the whole area crossed by the pad even in the condition of intermittent flux, approaching to the situation of constant heat flux. This explains the small influence of $\bar{A}$ on the coefficient of friction. On the contrary, at low pressure $(p=$ $15 \mathrm{MPa}$ ) and low velocities, where the rate of heat diffusion through the steel plate prevails, temperature rise and friction degradation are higher for smaller $\bar{A}$. It is worth noting that increasing the velocity from 50 to $200 \mathrm{~mm} / \mathrm{s}$ produces only a small change in the coefficient of friction, whereas the effect of a change in the applied pressure is more substantial.

The low sensitivity to change in velocity observed at high speeds is another effect of frictional heating. Due to the viscoelastic nature of the thermoplastic material of the pad, an increase in velocity naturally induces an increase in friction. But increasing the speed produces a proportional increase in the heat flux as well, according to Equation (2), and consequently the rate of energy dissipated as heat, which in turn rises the surface temperature and reduces the coefficient of friction. This explains the tendency of friction, above a certain velocity, to level off at an approximately constant value, according to a mechanism of thermal control of friction [Quaglini et al., 2014]. On the contrary, at low speeds energy dissipation is small and not sufficient to counterbalance the increase in friction due to viscoelastic effect.

\section{Effect of the distance}

Figure 4 shows the progress of the coefficient of friction versus the non-dimensional distance, calculated by assuming $d_{b d}=100 \mathrm{~mm}$. The consistent decrease of friction with the accrual of displacement observed whichever $\bar{A}$ (with a few exceptions discussed later) is an effect of heating of 
the sliding surface. Independently of the travelled distance $\bar{d}$, at moderate and high pressure the difference between the coefficient of friction observed on the scaled specimen and the coefficient of friction assessed on each FS prototype is less than $10 \%$, and this variation is deemed to be sufficiently small to be incorporated into the production and testing variability. Only at low pressure the effect of scaling can be substantial, and differently from the tests on the prototypes, the coefficient of friction of the small scale specimen tends to increase with increasing of $\bar{d}$, which is ascribed to wear of the sliding material. 

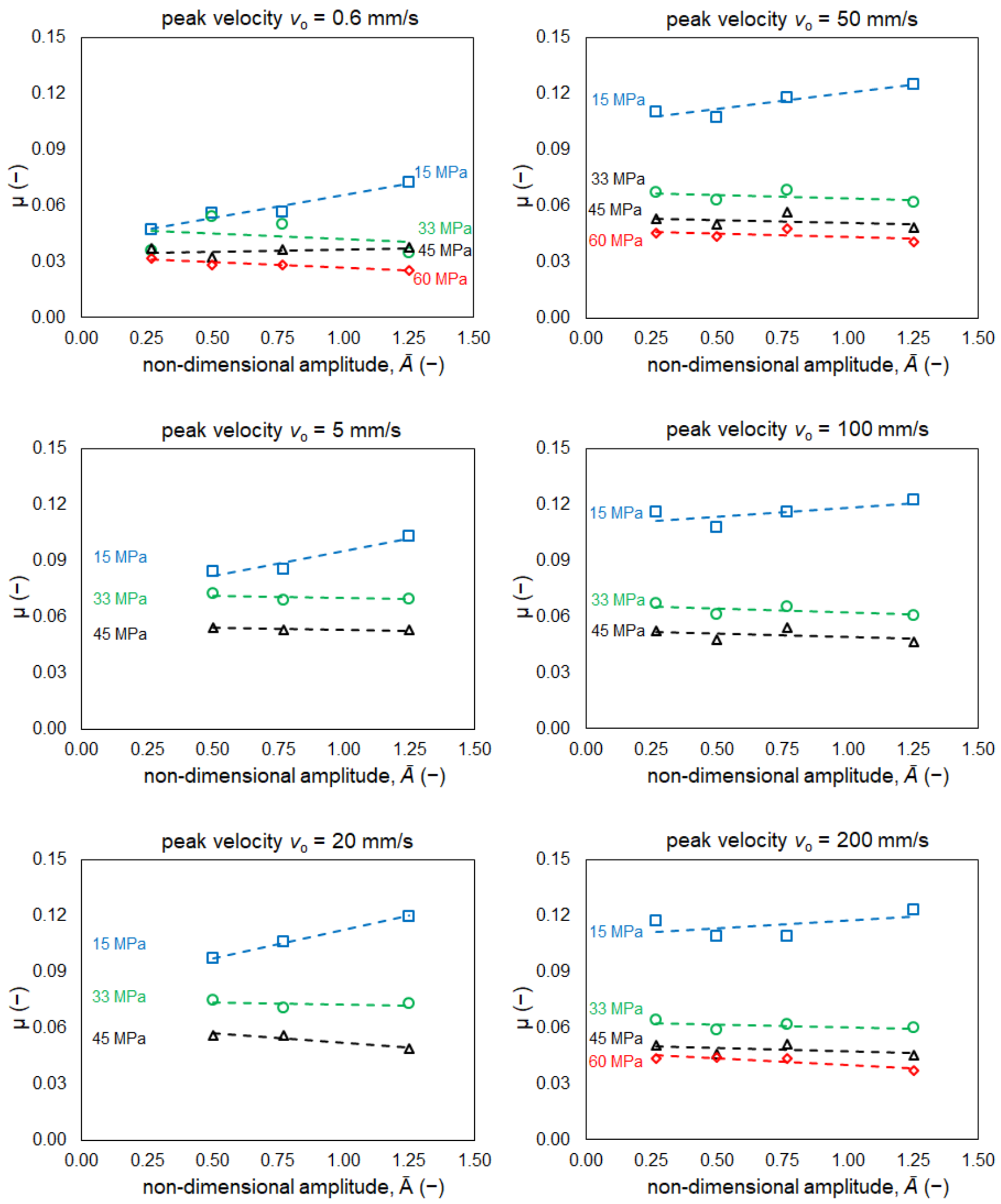

Figure 2. Coefficient of friction vs. non-dimensional amplitude evaluated at $\bar{d}=3\left(\bar{d}=1\right.$ for $v_{\mathrm{o}}=0.6$ mm/s) for MAT_A 

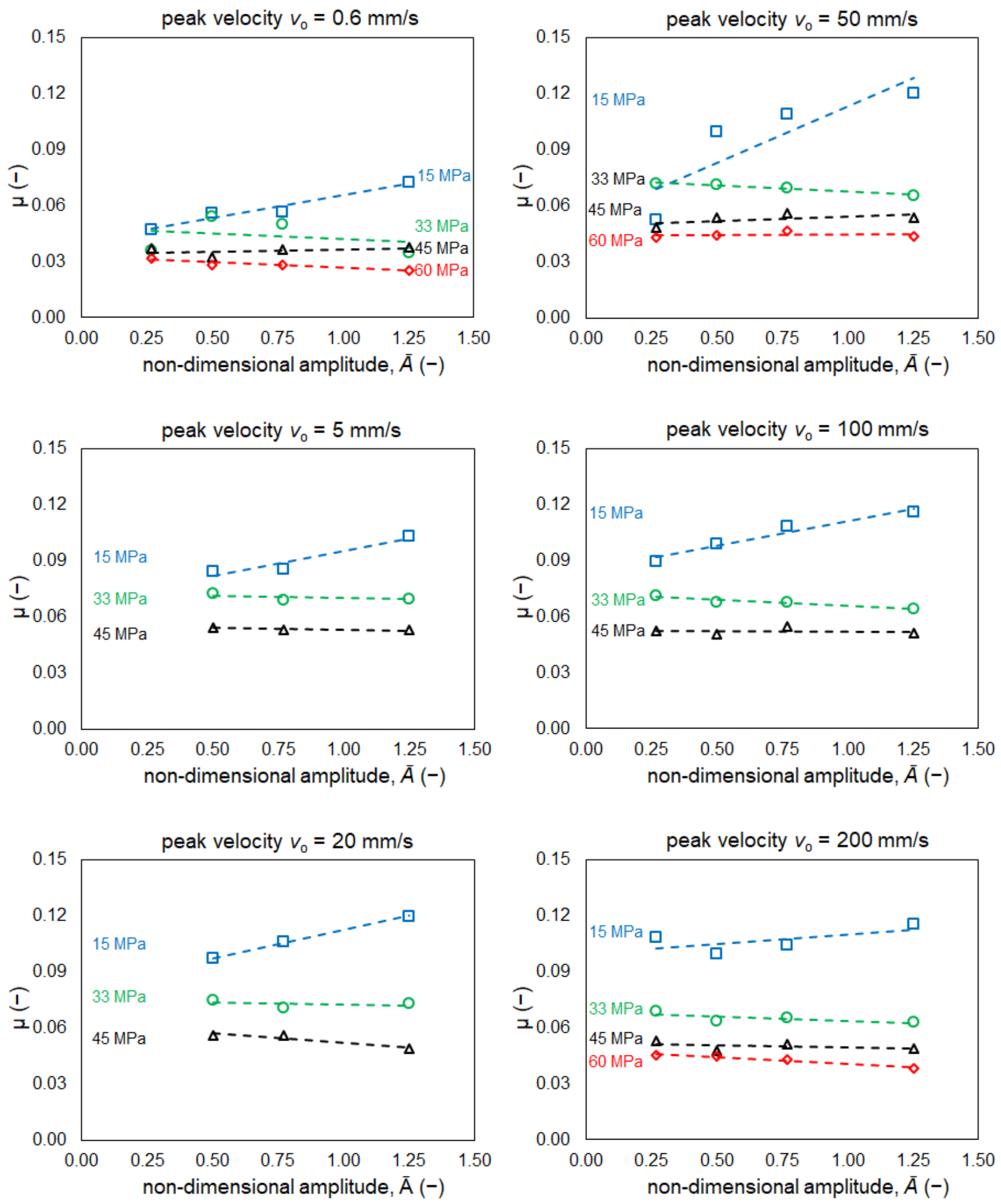

Figure 3. Coefficient of friction vs. non-dimensional amplitude evaluated at $\bar{d}=3\left(\bar{d}=1\right.$ for $v_{\mathrm{o}}=0.6$ $\mathrm{mm} / \mathrm{s}$ ) for MAT_B 

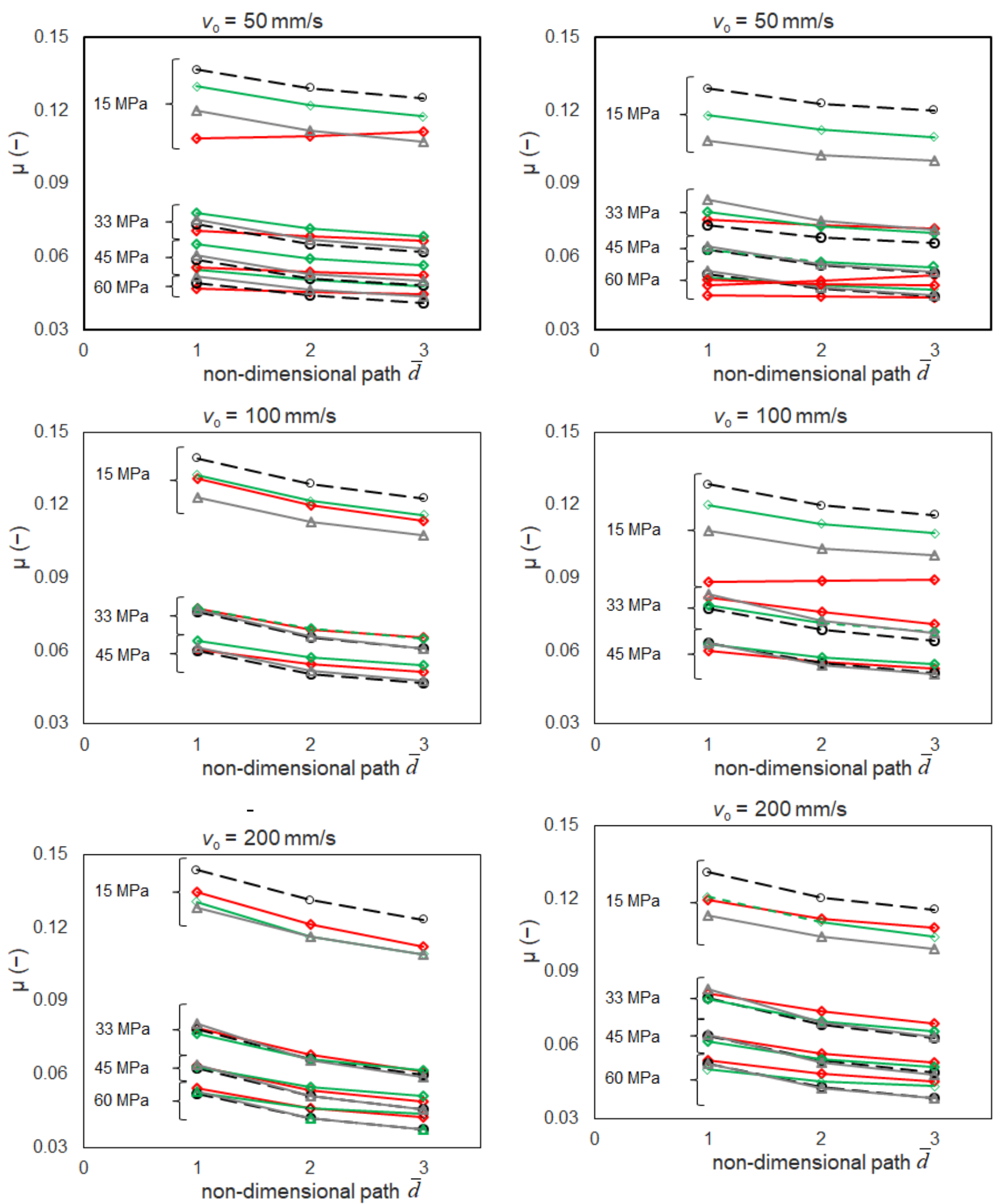

(a)

(b)

\begin{tabular}{llll|}
\hline$\rightarrow \hat{A}=0.27$ & $\Delta-\hat{A}=0.5 \quad \cdots \odot-\hat{A}=0.77 \quad-\ominus-\hat{A}=1.25$ \\
\hline
\end{tabular}

Figure 4. Coefficient of friction vs. non-dimensional distance $\bar{d}$ : (a) MAT_A; (b) MAT_B 


\section{Effect of the frequency}

Figure 5 shows the progress of the coefficient of friction versus the non-dimensional frequency $\bar{\omega}$ , assessed at various pressure levels and accrued movement.

By observing the plots for $\bar{d}=1$, two different trends can be noticed. At low values of $\bar{\omega}$, the coefficient of friction increases with increasing of $\bar{\omega}$, at higher rates for lower pressures. This trend reflects the viscoelastic behaviour of thermoplastic materials, which exhibits an increase in friction with the velocity of sliding. However, above a certain value of $\bar{\omega}$, a steady value seems to be approached according to the already anticipated mechanism of "thermal control of friction", and the influence of the frequency becomes less important. For $\bar{d}=3 \mu$ can be practically considered as independent of $\bar{\omega}$, because the cumulated heat flow supplied to the surface has eventually cancelled the effect of velocity. This effect is evident at moderate or high pressures, but at low pressure in presence of a small heat flux a steady thermal condition seems to have not yet been attained, and the influence of velocity on the final value of the coefficient of friction cannot be disregarded.

The experimental data points are fitted from a logarithmic function of type

$$
\mu=c \cdot \log (\bar{\omega})+b
$$

where coefficients $b$ and $c$ depend on the test conditions such as the applied pressure and the accumulated distance (Table 3 ). At $\bar{d}=1$ for both sliding materials the value of parameter $a$ at high pressure is not negligible ( $a=0.055$ for MAT_A, $a=0.048$ for MAT_B $)$, while at $\bar{d}=3$, the parameter $c$ ranges between $10^{-3}$ and $2 \times 10^{-4}$, confirming the substantial non influence of $\bar{\omega}$. 

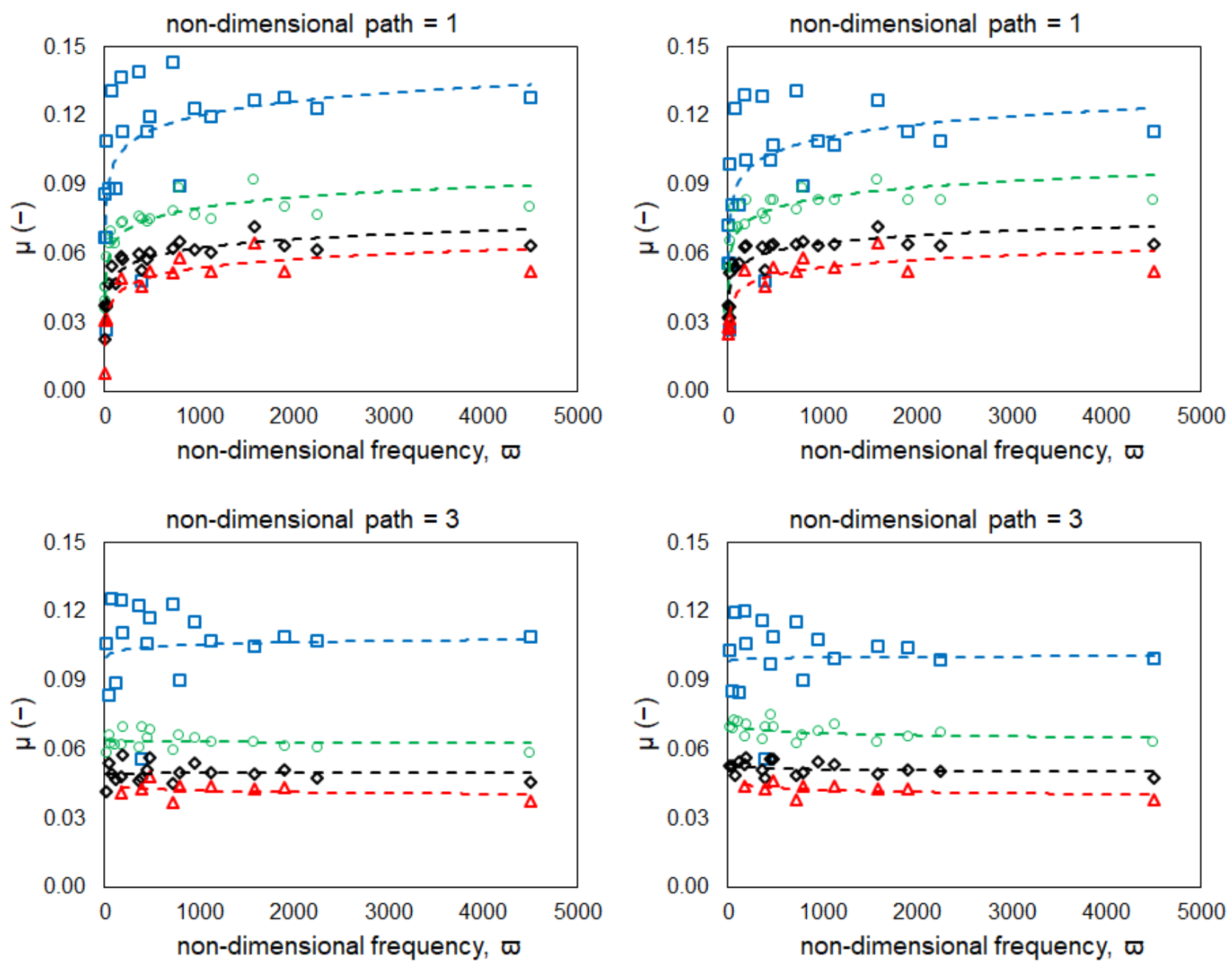

(a)

(b)

$$
\square p=15 \mathrm{MPa} \quad \circ p=33 \mathrm{MPa} \quad \diamond \mathrm{p}=45 \mathrm{MPa} \quad \Delta p=60 \mathrm{MPa}
$$

Figure 5. Coefficient of friction vs. non-dimensional frequency $\bar{\omega}$ : (a) MAT_A; (b) MAT_B 
Table 3. Effect of non-dimensional frequency: coefficients $c$ and $b$ in Equation (6).

\begin{tabular}{ccccc}
\hline material & $\begin{array}{c}\text { non-dimensional } \\
\text { distance } \\
\bar{d}\end{array}$ & pad pressure & & \\
& $(-)$ & $p$ & $c$ & $b$ \\
& & $(\mathrm{MPa})$ & $(-)$ & $(-)$ \\
\hline & 1 & 33 & 0.0090 & 0.0582 \\
& & 45 & 0.0065 & 0.0348 \\
MAT_A & 60 & 0.0054 & 0.0254 \\
& & 15 & 0.0055 & 0.0160 \\
\hline & 3 & 33 & 0.0011 & 0.0996 \\
& & 45 & -0.0002 & 0.0647 \\
& & 60 & 0.00010 & 0.0491 \\
& & 15 & 0.0087 & 0.0487 \\
\hline & & 33 & 0.0065 & 0.0504 \\
MAT_B & 45 & 0.0049 & 0.0312 \\
& & 60 & 0.0047 & 0.0214 \\
\hline & & 15 & 0.0001 & 0.1003 \\
& & 33 & -0.0010 & 0.0758 \\
& 3 & 45 & -0.0006 & 0.0559 \\
& & 60 & -0.0010 & 0.0518 \\
\hline
\end{tabular}

Table 4 provides a further assessment of scale effects by showing the ratio of the coefficient of friction measured on the scaled model to the average value of the coefficients of friction obtained from the prototypes. Values shaded in dark grey denote differences larger than $\pm 20 \%$, while values shaded in light grey correspond to differences between $\pm 10 \%$ and $\pm 20 \%$; all other values correspond to deviations less than $\pm 10 \%$. A good agreement is evident as concern the variation of the coefficient of friction with pressure, velocity and accumulated distance, with some appreciable deviation only at $p=$ $15 \mathrm{MPa}$.

At very low speed, when the non-dimensional amplitude has some influence, the coefficient of friction evaluated on the small scale specimen does not match the figure observed on real scale devices. For devices with MAT_B pads, a large mismatch is also observed at $p=15 \mathrm{MPa}$ for both $v_{\mathrm{o}}=50 \mathrm{~mm} / \mathrm{s}$ and $v_{\mathrm{o}}=100 \mathrm{~mm} / \mathrm{s}$ sliding speed, whereas for MAT_A the agreement is fair under the same conditions. 
The variation of the coefficient of friction observed on the prototypes between $\bar{d}=1$ and $\bar{d}=3$ is overestimated by the scaled model testing on average by $12 \%$ at $v_{\mathrm{o}}=50 \mathrm{~mm} / \mathrm{s}$, by $7 \%$ at $v_{\mathrm{o}}=100 \mathrm{~mm} / \mathrm{s}$ and by $3 \%$ at $v_{\mathrm{o}}=200 \mathrm{~mm} / \mathrm{s}$ for MAT_A, and by $15 \%$ at $v_{\mathrm{o}}=50 \mathrm{~mm} / \mathrm{s}$, by $6 \%$ at $v_{\mathrm{o}}=100 \mathrm{~mm} / \mathrm{s}$ and by $9 \%$ at $v_{\mathrm{o}}=200 \mathrm{~mm} / \mathrm{s}$ for MAT_B. The different performance of the scaled test can be explained as a consequence of the lower coefficient of friction of MAT_B: the heat flux is small and therefore the effect of the displacement amplitude in comparison to the size of the pad is not negligible. Nonetheless the small differences between the values of the friction coefficient observed at high speeds in tests implementing different figures of $\bar{A}$ confirm that the amplitude of motion is less essential in governing the thermal behaviour of sliding surfaces than the speed at which the heat source moves. 
Table 4. Comparison between scaled and prototype tests: ratio of the coefficient of friction measured on the scaled model (pad radius $a=37.5$ $\mathrm{mm}$ ) to the average coefficient of friction of prototype tests (pad radius: $a=80 / 130 / 200 \mathrm{~mm}$ )

\begin{tabular}{|c|c|c|c|c|c|c|c|c|c|c|c|c|c|}
\hline & & \multicolumn{3}{|c|}{$p=15 \mathrm{MPa}$} & \multicolumn{3}{|c|}{$p=33 \mathrm{MPa}$} & \multicolumn{3}{|c|}{$p=45 \mathrm{MPa}$} & \multicolumn{3}{|c|}{$p=60 \mathrm{MPa}$} \\
\hline & \multirow{2}{*}{$\begin{array}{c}\text { peak velocity } \\
v_{0}\end{array}$} & \multicolumn{3}{|c|}{ slide distance } & \multicolumn{3}{|c|}{ slide distance } & \multicolumn{3}{|c|}{ slide distance } & \multicolumn{3}{|c|}{ slide distance } \\
\hline & & $0.4 \mathrm{~m}$ & $0.8 \mathrm{~m}$ & $1.2 \mathrm{~m}$ & $0.4 \mathrm{~m}$ & $0.8 \mathrm{~m}$ & $1.2 \mathrm{~m}$ & $0.4 \mathrm{~m}$ & $0.8 \mathrm{~m}$ & $1.2 \mathrm{~m}$ & $0.4 \mathrm{~m}$ & $0.8 \mathrm{~m}$ & $1.2 \mathrm{~m}$ \\
\hline \multirow{4}{*}{ MAT_A } & $0.6 \mathrm{~mm} / \mathrm{s}$ & 0.38 & $=$ & $=$ & 0.84 & $=$ & $=$ & 1.13 & $=$ & $=$ & 1.24 & $=$ & $=$ \\
\hline & $50 \mathrm{~mm} / \mathrm{s}$ & 0.84 & 0.90 & 0.95 & 0.93 & 1.01 & 1.03 & 0.90 & 0.98 & 1.01 & 0.90 & 0.97 & 1.01 \\
\hline & $100 \mathrm{~mm} / \mathrm{s}$ & 1.00 & 0.99 & 0.98 & 1.01 & 1.03 & 1.05 & 0.97 & 1.02 & 1.04 & $=$ & $=$ & $=$ \\
\hline & $200 \mathrm{~mm} / \mathrm{s}$ & 1.00 & 1.00 & 0.99 & 1.01 & 1.03 & 1.02 & 1.01 & 1.02 & 1.03 & 1.04 & 1.07 & 1.07 \\
\hline \multirow{4}{*}{ MAT_B } & $0.6 \mathrm{~mm} / \mathrm{s}$ & 0.45 & $=$ & $=$ & 0.41 & $=$ & $=$ & 0.43 & $=$ & $=$ & 0.77 & $=$ & $=$ \\
\hline & $50 \mathrm{~mm} / \mathrm{s}$ & 0.41 & 0.45 & 0.48 & 0.96 & 1.02 & 1.04 & 0.80 & 0.85 & 0.89 & 0.84 & 0.92 & 0.96 \\
\hline & $100 \mathrm{~mm} / \mathrm{s}$ & 0.74 & 0.80 & 0.83 & 1.03 & 1.07 & 1.07 & 0.95 & 1.00 & 1.01 & $=$ & $=$ & $=$ \\
\hline & $200 \mathrm{~mm} / \mathrm{s}$ & 0.98 & 1.00 & 1.02 & 1.01 & 1.07 & 1.07 & 1.01 & 1.06 & 1.07 & 1.04 & 1.11 & 1.13 \\
\hline
\end{tabular}




\section{Discussion}

An approach to the experimental assessment of the coefficient of friction of sliding isolation system based on similarity has been investigated in the research. By applying the similarity theory, consistent values of the friction coefficient are observed in tests performed at different scales, provided that the same dimensionless groups that govern the physics of the systems have the same, or close, values.

The problem of the temperature rise at the contact surface between the slider and the mating plate which affects the coefficient of friction is described by three dimensionless variables, namely the nondimensional frequency $\bar{\omega}$ and the non-dimensional amplitude $\bar{A}$ which account for the characteristics of the motion, and the non-dimensional temperature $\bar{T}$, which accounts for the dependency of temperature on the heat flow at the sliding surface and on the thermal properties of the mating plate, and from an independent variable that is the contact pressure $p$ which influences the coefficient of friction according to an independent mechanism. Since the dimensionless parameters will stay constant for both the test and the application, they can be used to formulate scaling laws for the test.

The tests performed in the study demonstrated that in typical design situations of seismic isolation systems, the non-dimensional amplitude is of little importance and the coefficient of friction can be parametrized upon the accrued movement (here represented through the non-dimensional distance $\bar{d}$ ) and the non-dimensional frequency $\bar{\omega}$ for a given value of $p$.

The non-dimensional variable $\bar{\omega}$ is dependent on the dimension of the pad but is independent of the amplitude of motion. Since the Péclet number for oscillation motion is equal to the product $\bar{\omega} \bar{A}$, large values of $\bar{\omega}$ and thereby of $P e$ denote that the heat is introduced into the system faster than it is carried away from conduction through the steel plate, and thereby the temperature of the steel surface is therefore approximately constant over the whole area crossed by the slider. A practical implication is that at high speeds in the range of interest for seismic applications, the coefficient of friction experimentally determined on a reference device can be applied to devices at different scales and 
subjected to different design displacements provided the similarity conditions are met. The similarity concept can therefore be invoked for testing of scaled prototypes which is necessary in case of huge bearings exceeding the capacity of available facilities, including the establishment of unidirectional load histories which are equivalent, in terms of the temperature rise induced at the sliding surface, to the design bidirectional time history [Constantinou et al., 2007].

In the study, only prototypes of Flat Slider have been considered in order to reduce the experimental costs. Nonetheless, the results are expected to apply to Curved Surface Sliders as well, with some adaptations. While for the FS the coefficient of friction of the slider calculated by Eq. (4) coincides with the coefficient of friction of the sliding material assessed on the scaled FS model, for a CSS Eq. (4) provides an effective coefficient of friction of the bearing $\mu_{b}$ which accounts for the number and the curvature of the sliding surfaces, e.g. for a CSS with two curved surfaces the coefficient of friction of the sliding pads is related to $\mu_{b}$ according to the expression [Sarlis and Constantinou, 2016]

$$
\mu_{b}=\frac{\mu_{1} R_{1}+\mu_{2} R_{2}}{R_{1}+R_{2}-h}
$$

where $\mu_{i}$ and $R_{i}$ are the coefficient of friction of the sliding material pad and the radius of curvature of surface $i$, with $i=1$ or 2 , and $h$ is the height of the slider. However the extrapolation of the conclusions of the study to the CSS isolation system requires preliminarily a thorough investigation, which will be pursued in the next step of the study.

The experimental results presented in the paper demonstrated that the non-dimensional amplitude has a not significant influence on the coefficient of friction at least up to values of $\bar{A}$ as large as 1.25 , as shown in Figures 2 and 3. In spite this simplifying assumption disregards the existence of higher heat fluxes in areas subjected to more frequent and faster sliding activity, it proved to be effective for describing the actual friction degradation due to heating under high loads and high speeds. Although the Authors acknowledge that such conclusion cannot be applied to larger values of $\bar{A}$ than those assessed in the study without a further experimental validation, nonetheless it must be noted that the 
range $0.5 \leq \bar{A} \leq 1.25$ covers the design of a large number of slidingisolation systems with curved surfaces on the European market. The portfolios of some among the primary European manufacturers [Maurer, 2019, FIP, 2019, Mageba, 2019] were reviewed and for each device a design value of $\bar{A}$ was evaluated as the ratio of the claimed displacement capacity to the pad radius. Typical figures for $\bar{A}$ were found to range between 0.5 and 3.5, where higher values apply for isolators with low vertical load capacity (and hence with small pad), whereas isolators rated more than 5,000 kN vertical load present design figures of $\bar{A}$ between 0.5 and 1.5 .

Another practical implication of the study is that tests on scaled models can be used to characterize the coefficient of friction of the sliding materials used in production devices. The European Standard EN 15129 [CEN EN 15129, 2009] prescribes to test small specimens (75 mm diameter) to establish the coefficient of friction of the sliding material under service conditions (i.e. at low velocity); however, nothing is said about the suitability of the predictive performance of the scaled tests at large speeds. The study supports the claim that the scaled model procedure [Quaglini et al., 2012a] can estimate the coefficient of friction of production isolators with an accuracy better than $\pm 20 \%$ (and in most cases better than $\pm 10 \%$ ) at speeds higher than $100 \mathrm{~mm} / \mathrm{s}$ and pressures between 30 and $60 \mathrm{MPa}$, which represent practical design situations for sliding bearings for seismic applications. The European standard on antiseismic devices [CEN EN 15129, 2009] provides a tolerance of $\pm 20 \%$ on the design value of the coefficient of friction due to production variability, in addition to other sources of variability like temperature and aging. Thereby the scaled model procedure does not introduce a larger source of uncertainty on the coefficient of friction than the one expected owing to regular product variability. On the basis of these evaluations, the procedure is deemed to be validated.

Both the scaled model and the prototype testing according to the standards are exposed to the criticism that the coefficient of friction is determined along unidirectional trajectories, whereas during real earthquakes the motion usually follows bidirectional orbits which are supposed to produce more intermittent heat flux and consequently less friction degradation, especially when the amplitude of the 
motion is large in comparison to the size of the slider [Pavese et al., 2019, Furinghetti et al., 2019]. Though the cycling effect developed during a real multi-directional motion requires a specific experimental investigation, a preliminary adaptation of the similarity criterion could be extrapolated from the unidirectional formulation, following the argumentation proposed in [Lomiento et al., 2013]. In multi-directional movements, the velocity across the isolator is expressed by the vector $v=\left[v_{\mathrm{x}} ; v_{\mathrm{y}}\right]^{\mathrm{T}}$ and its modulus $|v|$ calculated in a nonlinear time history analysis can be used in Eq. (3b) in order to calculate the non-dimensional frequency $\bar{\omega}$, and the same can be done for the nondimensional path $\bar{d}$. If the non-dimensional groups $\bar{\omega}$ and $\bar{d}$ of the application and the test are equivalent, then the coefficient of friction from unidirectional tests could be used at a first approximation even for bidirectional motion. 


\section{CONCLUSIONS}

The study addresses the issue of scaling specimens and testing for the experimental assessment of the coefficient of friction of sliding isolation systems The investigation is restricted to unidirectional tests which are recommended by current standards for qualification and quality control purposes.

The main results of the research can be summarized as follows:

(a) similarity between unidirectional oscillating tests can be established based on some dimensionless variables, namely the non-dimensional frequency $\bar{\omega}$, the non-dimensional amplitude $\bar{A}$, and the non-dimensional temperature $\bar{T}$, plus the travelled distance $\bar{d}$ and the average pressure acting on the pad $p$;

(b) disregarding low pressure levels ( $p \leq 15 \mathrm{MPa}$ ) where the input energy is low, the nondimensional displacement amplitude $\bar{A}=A / a$ has little influence on the temperature growth, and thereby on the coefficient of friction during sustained sliding, at least in the range $0.25 \leq \bar{A} \leq$ 1.25 examined in the study;

(c) the duration of the motion, is an important parameter for the establishment of kinematic similarity, because of the temperature rise during the thermal transient; but once a thermal steady-state is attained, $\mu$ becomes independent of the travelled distance; during the transient period, the speed of testing can affect the coefficient of friction through the non-dimensional frequency $\bar{\omega}$, but if $\bar{\omega}$ is sufficiently great like under the effect of the seismic action the coefficient of friction becomes virtually independent of $\bar{\omega}$ even for short durations of excitation;

(d) provided that similarity conditions are satisfied, scaled models can be used for characterizing the coefficient of friction to be used in the design of sliding isolation systems. At high speeds typically $10 \% \sim 20 \%$ errors were found associated the extrapolation of the coefficient of friction to large size prototypes, which is acceptable in comparison to the $20 \%$ variation prescribed in the standards to account for regular production variability. 
The Authors acknowledge that the conclusions of the study are supported by a limited number of experiments, especially at the large scale, to be considered as generally validated, and hints for further investigation are addressed in the paper, in particular as concern the effect of large amplitude motions and bidirectional trajectories. 


\section{REFERENCES}

AASHTO Guide Specifications for Seismic Isolation Design, 4th Edition. [2014] American Association of State Highways and Transportation Officials, Washington, DC.

Al-Hussaini, T.M., Zayas, V.A., Constantinou, M.C. [2004] Seismic isolation of multi-story frame structures using spherical sliding isolation systems. Report No. NCEER-94-0007, National Center for Earthquake Engineering Research, Buffalo, New York.

ASCE/SEI 7 Minimum design loads for buildings and other structures [2017] American Society of Civil Engineers, Reston, Virginia.

Becker, T. C. and Mahin, S. A. [2012] "Experimental and analytical study of the bi-directional behavior of the triple friction pendulum isolator", Earthquake Engineering and Structural Dynamics, 41(3): 355-373, doi:10.1002/eqe.1133.

Benzoni, G. and Seible, F. [1998] Design of the Caltrans Seismic Response Modification Device (SRMD) test facility (IWGFR--96). International Atomic Energy Agency (IAEA), Wien, Austria.

Buckingham, E. [1914] "On physically similar systems; illustrations of the use of dimensional equations”, Physical Review 4(4), 345-376, doi:10.1103/PhysRev.4.345.

Buckle, A. and Mayes, R.L. [1990] "Seismic isolation: history, application, and performance - A world view”, Earthquake Spectra 6(2), 161-201, doi:10.1193/1.1585564.

Calvi, P.M. and Calvi, M. [2018] "Historical development of friction-based seismic isolation systems", Soil Dynamics and Earthquake Engineering 106, 14-30, doi:10.1016/j.soildyn.2017.12.003.

Calvi, G.M., Pavese, A., Ceresa, P., Dacarro, F., Lai, C.G., Beltrami, C. [2005] Design of a Largescale dynamic and pseudo-dynamic testing facility. IUSS Press, Pavia, Italy.

Carslaw, H.S. and Jaeger, J.C. [1959] Conduction of Heat in Solids, Oxford University Press. 
CEN EN 15129: Anti-Seismic Devices. [2009] European Committee for Standardization, Brussels, Belgium.

CEN EN 1337-2: Structural Bearings. Part 2: Sliding Elements. [2004] European Committee for Standardization, Brussels, Belgium.

Chang, J.C., Hwang, J.S., Lee, G.C. [1990] “Analytical model for sliding behaviour of Teflon stainless steel interfaces”, Journal of Engineering Mechanics 116(12): 2749-2763.

Constantinou, M.C., Whittaker, A.S., Kalpakidis, Y., Fenz, D.M., Warn, G.P. [2007] Performance of seismic isolation hardware under service and seismic loading. Report No. MCEER-07-0012, National Center for Earthquake Engineering Research, Buffalo, New York.

Dolce, M., Cardone, D., Croatto, F. [2005] "Frictional behaviour of steel-PTFE interfaces for seismic isolation”, Bulletin of Earthquake Engineering 3(1), 75-99, doi:10.1007/s10518-005-0187-9.

Dolce, M., Cardone, D., Marnetto, R. [2000] "Implementation and Testing of Passive control devices based on shape memory alloys", Earthquake Engineering and Structural Dynamics 29(7): 945-968, doi:10.1002/1096-9845(200007)29:7<945::AID-EQE958>3.0.CO;2-\#.

Fenz, D.M. and Constantinou, M.C. [2006] "Behaviour of the double concave Friction Pendulum bearing”, Earthquake Engineering and Structural Dynamics 35(11), 1403-1424, doi:10.1002/eqe.589. Fenz, D.M. and Constantinou, M.C. [2008] "Modeling triple friction pendulum bearings for responsehistory analysis", Earthquake Spectra 24(4), 1011-1028, doi:10.1193/1.2982531.

Fenz, D.M., Reed, R., Slatnick, S., Stewart, H.R., Constantinou, M.C. [2011] "Development of Performance-Based Testing Specifications for the Arkutun-Dagi Friction Pendulum Bearings", OTC Arctic Technology Conference, Houston, Texas.

FIP Industriale. Catalogue S04-Curved Surface Sliders, Padova, Italy. Available on-line at http://www.fipindustriale.it, 2019. 
Furinghetti, M., Pavese, A., Quaglini, V., Dubini, P. [2019] "Experimental investigation of the cyclic response of Double Curved Surface Sliders subjected to radial and bidirectional sliding motions", Soil Dynamics and Earthquake Engineering 117, 190-202, doi:10.1016/j.soildyn.2018.11.020.

Furinghetti, M. [2015] “Assessment and Modelling of the Seismic Response of Curved Surface Slider devices under Multi-Axial Input”, PhD Dissertation, IUSS Istituto Universitario Studi Superiori, Pavia, Italy.

Gandelli, E., Penati, M., Quaglini, V., Lomiento, G., Miglio, E., Benzoni, G.M. [2018] “A novel OpenSees element for single curved surface sliding isolators", Soil Dynamics and Earthquake Engineering 119, 433-453, doi:10.1016/j.soildyn.2018.01.044.

Harris, H.G. and Sabnis G. [1999] Structural Modeling and Experimental Techniques. $2^{\text {nd }}$ Edition, CRC Press, Boca Raton, Florida.

Incoprera, F.P., and DeWitt, D.P. [2007] Fundamentals of Heat and Mass Transfer, 6th Edition. John Wiley \& Sons, Inc., New York.

Jaeger, J.C. [1942] "Moving sources of heat and temperature at sliding contacts", Proceedings of the Royal Society of NSW 76, 203-224.

Jangid, R.S. [1996] "Seismic response of sliding structures to bi-directional earthquake excitations", Earthquake Engineering and Structural Dynamics 25(11), 1301-1306, doi:10.1002/(SICI)10969845(199611)25:11<1301::AID-EQE618>3.0.CO;2-3.

Kumar, M., Whittaker, A.S., Constantinou, M.C. [2015] "Characterizing friction in sliding isolation bearings", Earthquake Engineering and Structural Dynamics 44(9), 1409-1425, doi:10.1002/eqe.2524. Lomiento, G., Bonessio, N., Benzoni, G. [2013] "Friction model for sliding bearings under seismic excitation", Journal of Earthquake Engineering 17(8) 1162-1191, doi:10.1080/13632469.2013.814611. 
Mageba SA. Prospect Reston Pendulum, Bulach, Switzerland. Available on-line at: http://www.mageba.ch/data/docs/en_CH/2575/PROSPECT-RESTON-PENDULUM-ch-en.pdf), 2019.

Maurer Sohne. MAURER Curved Surface Slider SIP®-D brochure, Munchen, Germany. Available on-line at: https://www.maurer.eu/fileadmin/mediapool/downloads/TI_004_EN_MAURER_SIPD_online.pdf, 2019.

Martelli, A., Clemente, P., De Stefano, A., Forni, M., Salvatori, A. [2014] "Recent development and application of seismic isolation and energy dissipation and conditions for their correct use", Perspectives on Earthquake Engineering and Seismology - Ansal A. (editor) 1, 449-488, Springer: New York.

McKenna, F., Fenves, G.L., Scott, M.H., Jeremic, B., [2000] “Open System for Earthquake Engineering Simulation (OpenSees)" Pacific Earthquake Engineering Research Center (PEER), Berkeley, California.

Mokha, A.S., Avin, N., Constantinou, M.C., Zayas, V. [1996] "Seismic isolation retrofit of a large historical building”, ASCE Journal of Structural Engineering 122(3), 298-308, doi:10.1061/(ASCE)0733-9445(1996)122:3(298).

Mokha, A.S., Constantinou, M.C., Reinhorn, A. [1998] "Teflon bearings in aseismic base isolation: experimental studies and mathematical modelling”, Report No. NCEER-880038, National Center for Earthquake Engineering Research, Buffalo, New York.

Mokha, A.S., Constantinou, M.C., Reinhorn, A. [1990] “Teflon Bearings in Base Isolation I: Testing” Journal of Structural Engineering ASCE 116(2), 438-454, doi:10.1061/(ASCE)0733-9445.

Mokha, A.S., Constantinou, M.C., Reinhorn, A.M. [1991] "Experimental study of friction-pendulum isolation system", Journal of Structural Engineering ASCE 117(4), 1201-1217, doi:10.1061/(ASCE)0733-9445(1991)117:4(1201). 
Mokha, A.S., Constantinou, M.C., Reinhorn, A.M. [1993] "Verification of friction model of teflon bearings under triaxial load" Journal of Structural Engineering ASCE 119(1), 240-261, doi:10.1061/(ASCE)0733-9445(1993)119:1(240).

Morgan, T. A. and Mahin, S. A. [2010] “Achieving reliable seismic performance enhancement using multi - stage friction pendulum isolators", Earthquake Engineering and Structural Dynamics, 39(13): 1443-1461, doi:10.1002/eqe.1043.

Mosqueda, G., Whittaker, A.S., Fenves, G.L. [2004a] "Characterization and modeling of friction pendulum bearings subjected to multiple components of excitation” Journal of Structural Engineering ASCE 130(3), 433-442, doi:10.1061/(ASCE)0733-9445(2004)130:3(433).

Mosqueda, G., Whittaker, A.S., Fenves, G.L., Mahin, S.A. [2004b] "Experimental and Analytical Studies of the Friction Pendulum System for the Seismic Protection of Simple Bridges" Report No. UCB/EERC 2004-01, Earthquake Engineering Research Center, University of California at Berkeley, California.

Mostaghel, N. and Tanbakuchi, J.T. [1983] "Response of sliding structures to earthquake support motion", Earthquake Engineering and Structural Dynamics 11(6), 729-748, doi:10.1002/eqe.4290110603.

Mostaghel, N. [1984] “Resilient-Friction base isolator”, Report No. UTEC 84/97, Department of Civil Engineering University of Utah, Utah.

Pavese, A., Furinghetti, M., Casarotti, C. [2019] "Experimental assessment of the cyclic response of friction-based isolators under bidirectional motions", Soil Dynamics and Earthquake Engineering 114, 1-11, doi:10.1016/j.soildyn.2018.06.031. 
Ponzo, F. C., Di Cesare, A., Leccese, G., and Nigro, D. [2017] "Shake table testing on restoring capability of double concave friction pendulum seismic isolation systems", Earthquake Engineering and Structural Dynamics, 46(14): 2337- 2353, doi:10.1002/eqe.2907.

Quaglini, V., Gandelli, E., Dubini, P. [2019] "Numerical investigation of curved surface sliders under bidirectional orbits", International Journal of Earthquake Engineering - Ingegneria Sismica XXXVI(2), 118-136.

Quaglini, V., Gandelli, E., Dubini, P. [2017a] "Experimental investigation of the re-centring capability of curved surface sliders", Structural Control and Health Monitoring 24(2), e1870, doi:10.1002/stc. 1870 .

Quaglini, V., Gandelli, E., Dubini, P., Limongelli, M.P. [2017b] “Total displacement of curved surface sliders under nonseismic and seismic actions: A parametric study", Structural Control and Health Monitoring 24(12), e2031, doi:10.1002/stc.2031.

Quaglini, V., Bocciarelli, M., Gandelli, E., Dubini, P. [2014] "Numerical assessment of frictional heating in sliding bearings for seismic isolation” Journal of Earthquake Engineering 18(8), 1198-1216, doi:10.1080/13632469.2014.924890.

Quaglini, V., Dubini, P., Ferroni, D., Poggi, C. [2009] "Influence of counterface roughness on friction properties of engineering plastics for bearing applications”, Materials and Design 30(5), 1650-1658, doi:10.1016/j.matdes.2008.07.025.

Quaglini, V., Dubini, P., Poggi, C. [2012a] "Experimental assessment of sliding materials for seismic isolation systems" Bulletin of Earthquake Engineering 10(2), 717-740, doi:10.1007/s10518-0119308-9.

Quaglini, V. [2012b] "High damping curved surface sliding isolators for bridges” Bridge Maintenance, Safety, Management, Resilience and Sustainability: Proceedings of the Sixth International IABMAS Conference, Stresa, Italy. 
SAP2000 v. 15 [2013] Computers and Structures Incorporated (CSI). Berkeley, California.

Sarlis, A.A. and Constantinou, M.C. [2016] "A model of triple friction pendulum bearing for general geometric and frictional parameters" Earthquake Engineering Structural Dynamics 45(11), 18371853, doi: 10.1002/eqe.2738.

Tsai, C.S. [1997] "Finite element formulations for friction pendulum seismic isolation bearings" International Journal for Numerical Methods in Engineering 40(1), 29-49, doi:10.1002/(SICI)10970207(19970115)40:1<29::AID-NME47>3.0.CO;2-A.

Wen, J., Han, Q. and Du, X. [2019] "Shaking table tests of bridge model with friction sliding bearings under bi-directional earthquake excitations" Structure and Infrastructure Engineering 15(9), 12641278, doi:10.1080/15732479.2019.1618350.

Wen, J. and Khonsari, M.M. [2007] "Transient temperature involving oscillatory heat source with application in fretting contact", ASME Journal of Tribology 129(3), 517-527, doi:10.1115/1.2736435. Westermo, B. and Udwadia, F. [1983] "Periodic response of a sliding oscillator system to harmonic excitation" Earthquake Engineering and Structural Dynamics 11(1), 135-146, doi:10.1002/eqe.4290110111.

Younis, C.J. and Tadjbakhsh, I.G. [1984] "Response of sliding structures to base excitation", Journal of Engineering Mechanics ASCE 110(3), 401-418, doi:10.1061/(ASCE)07339399(1984)110:3(417).

Zayas, V.A., Low, S.S., Mahin, S.A. [1987] "The FPS earthquake protection system: experimental report" Report No. UCB/EERC-87/01, Earthquake Engineering Research Center, University of California at Berkeley, California.

Zayas, V.A., Low, S.S., Mahin, S.A. [1990] "A simple pendulum technique for achieving seismic isolation”, Earthquake Spectra 6(2), 317-333, doi:10.1193/1.1585573. 
Zayas, V.A., Low, S.S., Bozzo, L., Mahin, S. [1989] "Feasibility and performance studies on improving the earthquake resistance of new and existing buildings using the friction pendulum system”, Report No. UCB/EERC-89/09, Earthquake Engineering Research Center, University of California at Berkeley, California. 